\title{
CAMBRIDGE
}

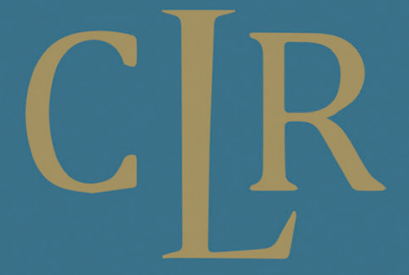

\section{CAMBRIDGE LAW REPORTS}

A new way to access essential international law resources

\section{Get exclusive access to the leading International Law} Reports and ICSID reports first via Cambridge Law Reports (CLR)

CLR offers extensive search options, a unique browse feature to quickly find required content and a personal folder for saving key cases and searches.

\section{Exclusive} CLR Features

- Browse by court, judge, party and subject keyword

- Citation look-up

- Site responds to your preferred device, including smartphones

- Download full-text PDFs or citations

- Save searches and cases to personal folders
Features

For Librarians

- ATHENS and Shibboleth compatible

- In house MARC and KBART records

- Library administrator tools available

- Technical support, onsite help, FAQs and user statistics

- Usage reporting

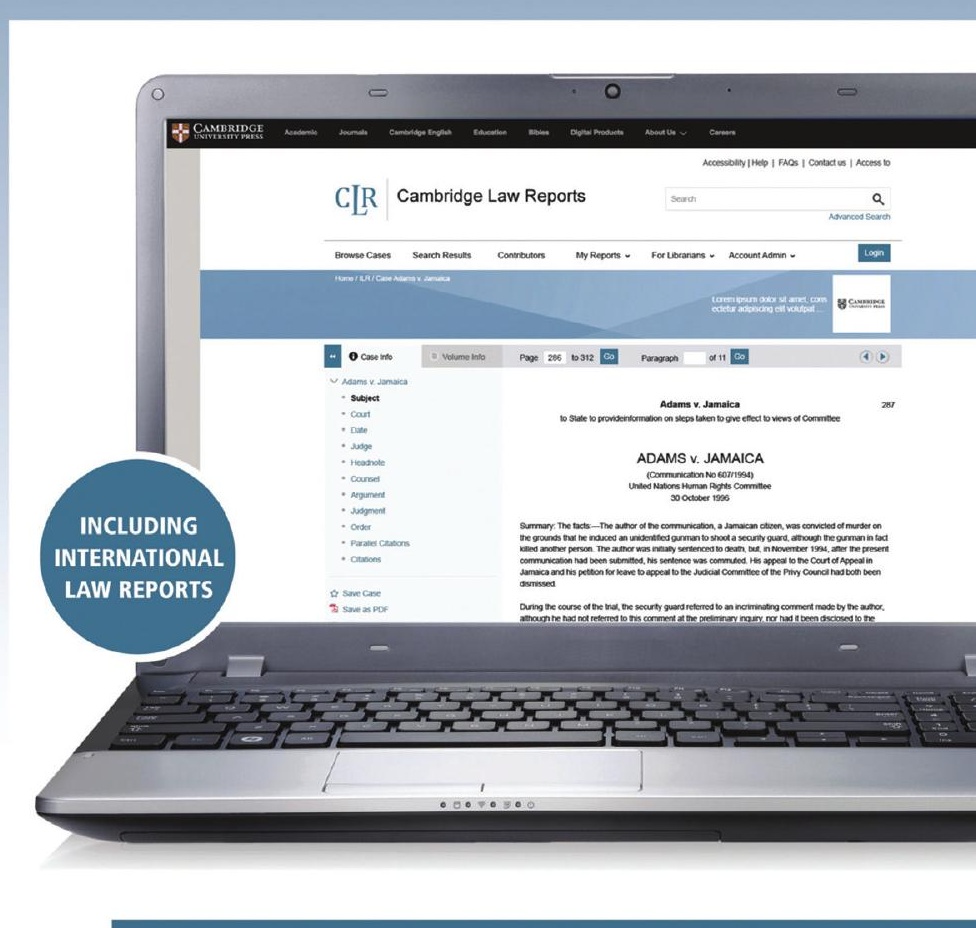

For more information and purchasing options, speak to your sales representative or contact: In the Americas: online@cambridge.org

Rest of World:

library.sales@cambridge.org 